\title{
A 62 Year Old Nigerian Male Presenting With Empty Sella Syndrome and Myxedema Crisis: A Case Report
}

\author{
Akhidue $\mathrm{K}^{1}$, Owhonda. $\mathrm{G}^{1}$, Gomba V. $\mathrm{E}^{1}$, Daka. $\mathrm{I}^{1}$, Amachree I. B ${ }^{1}$, Alikor C. $\mathrm{A}^{2^{*}}$ \\ ${ }^{1}$ Department of Internal medicine, Rivers State University Teaching Hospital Port Harcourt, Nigeria \\ ${ }^{2}$ Department of Medicine, University of Port Harcourt, University of PMB 5323 Choba, East-West Rd, Port Harcourt, Nigeria
}

DOI: $10.36348 /$ sjbr.2020.v05i02.002

| Received: 03.02.2020 | Accepted: 19.02.2020 | Published: 25.02 .2020

*Corresponding author: Alikor C. A

\section{Abstract}

Empty sella syndrome is a condition in which the pituitary gland appears to be partially or totally absent from the pituitary fossa. It is a misnomer in that, the sella is not truly empty, but filled with cerebrospinal fluid and as such, the pituitary gland is flattened or shrunken and hence not visualized on imaging. In most cases, it is asymptomatic and found on imaging as an incidental finding. In symptomatic cases it may present with headaches, CSF rhinorrhoea, visual field defects or partial or panhypopituitarism. Here we report a case of a 62 year old Nigerian male who presented with hemiparesis, and CT evidence of empty sella syndrome and myxedema crises.

Keywords: Empty sella syndrome; hypothyroidism; myxedema crisis.

\begin{abstract}
Copyright @ 2020: This is an open-access article distributed under the terms of the Creative Commons Attribution license which permits unrestricted use, distribution, and reproduction in any medium for non-commercial use (NonCommercial, or CC-BY-NC) provided the original author and source are credited.
\end{abstract}

\section{BACKGROUND}

Empty sella syndrome is a rare syndrome characterized by an enlarged sella turcica that is partially or completely filled with cerebrospinal fluid $[1,2]$. The sella turcica or Pituitary fossa is a saddle shaped space at the base of the skull that houses the pea sized master gland -the pituitary gland [3]. In empty sella syndrome there is herniation of the arachnoid into the sella space leading to compression, displacement and possibly damage of the pituitary gland [4]. It is actually a misnomer as the sella is not truly empty but filled with cerebrospinal fluid making the pituitary gland not readily visualized on CT or MRI scans. It is usually an incidental neuro-radiologic finding but can be associated with abnormal pituitary function [5].

The syndrome was $1^{\text {ST }}$ described in 1949 by Harold Leeming Sheehan (1900-1988) a British pathologist and Vincent Summers a consulting physician (1914-1975). They both studied cases of pituitary gland destruction including in those with Sheehan's syndrome a rare complication of pregnancy $[6,7]$. They found that the pituitary fossa (sella turcica) in these patients was filled with CSF instead of the usual soft tissue of the pituitary gland. However it was not until 1951 that the name empty sella was coined by Busch [8].
The prevalence of ESS ranges from 5.5 to $35 \%$ in autopsy/ voluntary MRI series [9]. It has a female preponderance with a female to male ratio of $4: 1$ and occurs more in middle aged adults $[4,9]$.

The two main pathophysiologic processes involved in the pathogenesis of empty sella syndrome are; weakness of the diaphragmatic sella and /or raised intracranial pressure $[4,10]$. These could be congenital or acquired and therefore classified as either primary or secondary.

Primary empty sella syndrome represents empty sella syndrome with no discernable cause. It is the commonest cause of an enlarged sella turcica and results from congenital incompetence of the diaphraghmatic sella and or increased intracranial pressure. Primary empty sella syndrome is generally found in conditions associated with intermittent increase in intra cranial pressure such as obesity, arterial hypertension obstructive sleep apnoea, pregnancy, labour and multiparity $[1,4,10]$. It is thus more commonly seen in middle aged women and may be a sign of benign idiopathic intracranial hypertension (Up to $50 \%$ of patients with primary empty sella syndrome have benign intracranial hypertension). 
Secondary empty sella syndrome is more common than primary. It results from acquired causes such as treatment of pituitary tumors with drugs, pituitary surgery, or irradiation, autoimmune pituitary destruction, Sheehan's syndrome. Pituitary adenomas undergoing spontaneous necrosis (infarction or haemorhage), pituitary infections, traumatic brain injury etc [10]. This usually presents with features of loss of pituitary function such as, amenorrhoea, infertility, fatigue, intolerance to stress and infection [8].

ESS can also be classified as either partial or complete based on the proportion of the sella filled with CSF. In partial ESS, less than $50 \%$ of the sella is filled with CSF and the gland has a thickness of $3-7 \mathrm{~mm}$ (small but present normal gland) while in total EES, more than $50 \%$ of the sella is filled with CSF and the gland thickness is less than $2 \mathrm{~mm}$.

Most cases of empty sella syndrome are discovered incidentally following a CT or MRI evaluation for headache, neurological symptom, visual disturbance or an endocrine abnormality. Most cases of ESS especially Primary ESS are asymptomatic. Symptoms depend on the degree of involvement of the pituitary and optic structures. Headache is the most common symptom and usually has a coincidental relationship to ESS but can be due to raised intracranial pressure [1, 11]. 25-50\% have endocrine dysfunction (Features of hypopituitarism, hyperprolactinaemia) Visual field defects, Spontaneous Csf rhinorrhoea, meningitis and psychiatry disturbance can also occur $[12,13]$.

The radiologic diagnosis of ESS is made using an MRI of the pituitary preferably. But a CT scan can suffice in the absence of MRI scan. In patients with positive imaging result, test of anterior pituitary function is further needed to assess pituitary function.

\section{CASE SUMMARY}

A 62 year old male who presented with a one week history of sudden onset weakness of the right upper and lower limb with associated numbness. There was no history of headache, vomiting, facial deviation, slurred speech seizures or altered consciousness. He was a known hypertensive of long standing with poor adherence to therapy but had not had a TIA or stroke in the past. He admitted to a history of recurrent pedal oedema for the past five years with dyspnoea on exertion, but no cough, paroxysymal nocturnal dyspnoea or othopnoea. He also had periorbital swelling, cold intolerance, weight gain, lethargy and hyperpigmentation of the face and foot.

On examination he was pale with periorbital swelling, pedal oedema and hyperpigmentation of the face and foot. He was conscious, alert and well oriented with no obvious cranial nerve deficit but with subtle right sided hemiparesis. He had a normal pulse rate (76bpm, regular), an elevated blood pressure $(\mathrm{BP}=170 / 95 \mathrm{mmHg}$ ), cardiomegaly (6LICS AAL non heaving) and fine bibasal crepitations.

\section{RESULTS OF INVESTIGATIONS CT SCAN REPORT}

The only CT scan finding was a CSF filled sella turcica with the pituitary gland compressed against its floor. The cerebral and cerebellar hermispheres were normal.

\section{HORMONE PROFILE AND OTHER ANCILLARY INVESTIGATIONS}

Homone profile showed primary hypothyroidism viz: Free T3 -<0.4 (2.8-7.1pmol/1), Free T4 -1.3 (10.6-22pmol/l) and TSH- 37.74(0.274.2U/IU/L) and mildly reduced serum testosterone levels. Basal cortisol, ACTH, IGF, prolactin, LH and FSH were all within normal limits. His full blood count result was normal except for anaemia -(PCV 27\%). Lipid panel showed elevated total cholesterol $(6.76 \mathrm{mmol} / \mathrm{l})$ and low density lipoprotein cholesterol $(5.18 \mathrm{mmol} / \mathrm{l})$. He had impaired renal function $\left(\mathrm{eGFR}=25 \mathrm{mls} / \mathrm{min} / 1.73 \mathrm{~m}^{2}\right)$ and hyponatraemia $(121 \mathrm{mmol} / \mathrm{l})$. There was echocardiographic evidence of eccentric hypertrophy of left ventricular geometry with Systolic dysfunction $(\mathrm{EF}=44 \%)$. No evidence of pericardial effusion.

\begin{tabular}{|l|l|l|}
\hline HORMONE & RESULT & REFERENCE RANGE \\
\hline TSH & 37.74 & $0.27-4.2 \mathrm{U} / \mathrm{IU} / \mathrm{L}$ \\
\hline FREE T3 & $<0.4$ & $(2.8-7.1 \mathrm{pmol} / \mathrm{l})$, \\
\hline FREE T4 & 1.3 & $10.6-22 \mathrm{pmol} / 1$ \\
\hline FSH & $3.2 \mathrm{U} / \mathrm{L}$ & $(1.5-12.4)$ \\
\hline LH & $6.4 \mathrm{U} / \mathrm{L}$ & $(1.7-8.6)$ \\
\hline TESTOSTERONE & $5.2 \mathrm{nmol} / \mathrm{L}$ borderline $\downarrow$ & $5.3-19.6$ \\
\hline PROLACTIN & $10.2 \mathrm{ng} / \mathrm{ml}$ & \\
\hline ACTH & $11.6 \mathrm{pg} / \mathrm{ml}$ & $(2.8-64.6)$ \\
\hline BASAL CORTISOL & $12.53 \mathrm{ug} / \mathrm{dl}$ & $(7-28)$ \\
\hline IGF & $163 \mathrm{ng} / \mathrm{ml}$ & $(51-187)$ \\
\hline
\end{tabular}


RESULT OF ELECTROLYTES, RENAL FUNCTION AND LIPID PANEL

\begin{tabular}{|l|l|l|}
\hline TEST & RESULT & REFERENCE RANGE \\
\hline T. CHOL & $6.76 \mathrm{mmol} / \mathrm{l}$ & $<5.17$ \\
\hline TG & $1.09 \mathrm{mmol} / \mathrm{l}$ & $<\mathbf{1 . 7 1}$ \\
\hline LDL & $5.18 \mathrm{mmol} / \mathrm{l}$ & $<3.30$ \\
\hline HDL & $1.08 \mathrm{mmol} / 1$ & $\mathbf{1 . 0 4 - 1 . 5 5}$ \\
\hline SODIUM & $\mathbf{1 2 1} \mathbf{~ m m o l} / \mathrm{l}$ & $\mathbf{( 1 2 8 - 1 4 8 )}$ \\
\hline POTASSIUM & $\mathbf{3 . 4} \mathbf{~ m m o l} / \mathbf{l}$ & $\mathbf{( 3 . 5 - 4 . 8 )}$ \\
\hline UREA & $5.18 \mathrm{mmol} / 1$ & $\mathbf{( 1 . 5 - 6 . 6 )}$ \\
\hline CREATININE & $185 \mathrm{mmol} / 1$ & $(\mathbf{6 0 - 1 2 0})$ \\
\hline
\end{tabular}

\section{TREATMENT}

$\mathrm{He}$ was initially placed on $25 \mathrm{ug}$ of levothyroxine, lipid lowering agent (a statin), antiplatelet and diuretics but while he was still being evaluated, he developed features of myxedema crises (loss of consciousness, hypotension, hypothermia) and was managed with oral levothyroxine 50ug (in the absence of parenteral levothyroxine), IV hydrocortisone, glucose infusion, antibiotics with other supportive care. He responded well to the treatment and was maintained on 100ug of levothyroxine and $5 \mathrm{mg}$ prednisolone at discharge. He is currently euthyroid with normal lipid profile and normal renal function though still has residual hemiparesis.

\section{DISCUSSION}

The initial working diagnosis of this patient was a cerebrovascular accident based on the presentation of sudden onset hemiparesis on background of hypertensive heart disease and dyslipidaemia. However cranial CT ruled out a stroke. This case highlights the typical presentation of ESSusually an incidental finding on radio-imaging. Neuroendocrine disturbance such as hypopituituarism and hyperprolactinaemia (which may be due to a hypersecretory microadenoma) are common findings in empty sella syndrome.

Hypopituituarism is a clinical syndrome of deficient production of one or more of the pituitary hormones. It is commoner than hyperprolactinaemia in the setting of empty sella syndrome. The presentation of hypopituituarism varies from asymptomatic to acute collapse. It could be isolated (deficiency of only one pituitary hormone) partial (deficiency of 2 or more pituitary hormones) or panhypopituituarism (deficiency of all pituitary hormones). The commonest hormonal deficiency in hypopituituarism is growth hormone deficiency. The usual pattern of hormonal deficiency in hypopituituarism is in the order -Growth hormone, gonadotrophins, thyroid stimulating hormone, adrenocorticotropic hormone, prolactin, followed by posterior pituitary hormone.

Myxedema crises is a severe, life threatening manifestation of hypothyroidism. It may be the $1^{\text {st }}$ presentation in previously undiagnosed hypothyroid as was seen in this case. It can also occur in patients with poorly treated hypothyroidism.

This case highlights the finding of undiagnosed primary hypothyroidism in the setting of empty sella syndrome. We hypothesise that this patient had secondary empty sella syndrome with primary hyperthyroidism of autoimmune origin

This patient had classic features of long standing undiagnosed hypothyroidism. He had unexplained weight gain, cold intolerance hyperpigmentation and a myxedema crises. In this case the diagnosis of hypothyroism was only made following the work up for the incidental finding of ESS.

Hypothyroidism as was seen in this case report is a common endocrine manifestation in patients with ESS. Most cases are central as part of hypopituituarism. Primary hypothyroidism is rare. Milosevic et al had reported a case series of 3 patients with primary hypothyroidism and ESS. These patients all had panhypopituituarism. Primary hypothyroidism can preceed hypopituituarism, occur at same time or several years after development of hypopituituarism. Primary hypothyroidism preceeding ESS or hypopituituarism usually results from secondary enlargement of the pituitary gland due to prolonged untreated hypothyroidism. There is also an established relationship between ESS and primary autoimmune hypothyroidism such that there is a common pathogenesis leading to simultaneous pituitary and thyroid gland destruction. Empty sella syndrome can also be a consequence of treatment of primary hypothyroidism using levothyroidism in patients with hyperprolactinaemia

Generally the treatment of ESS depends on the type and clinical manifestations. No specific treatment is necessary in asymptomatic patients with normal pituitary function. However patients with pituitary dysfunction will however require replacement of the deficient hormones and treatment of hyperprolactinaemia if present. Surgical treatment may also be necessary in patients with complicating CSF rhinorrhoea or visual field defect. The prognosis of empty sella syndrome is generally good especially in patients with primary empty sella syndrome. For 
patients with the secondary form, prognosis depends on underlying cause.

\section{CONCLUSION}

Empty sella syndrome is a rare finding in clinical practice. This is the first reported case in Nigeria from our knowledge. It is most times an incidental finding as was in this case. Primary hypothyroidism is not a usual finding but may present even as myxedema crises.

\section{REFERENCES}

1. Empty Sella Syndrome - NORD (National Organization for Rare Disorders). [cited $2020 \mathrm{Feb}$ 10]. Available from: https://rarediseases.org/rarediseases/empty-sella-syndrome

2. Fouad, W. (2011). Review of empty sella syndrome and its surgical management. Alexandria Journal of Medicine, 47(2):139-147.

3. Ganapathy MK, Tadi P. Anatomy, Head and Neck, Pituitary Gland. StatPearls. StatPearls Publishing; 2020 [cited 2020 Feb 10]. Available from: http://www.ncbi.nlm.nih.gov/pubmed/31855373

4. Ucciferro, P., \& Anastasopoulou, C. Empty Sella. StatPearls. StatPearls Publishing; 2020 [cited 2020 Feb 10]. Available from: http://www.ncbi.nlm.nih.gov/pubmed/31082046

5. Aruna, P., Sowjanya, B., Reddy, P. A., Krishnamma, M., \& Naidu, J. N. (2014). Partial empty sella syndrome: a case report and review. Indian Journal of Clinical Biochemistry, 29(2), 253-256.

6. Micheal CO MK. Pituitary Disorders: Diagnosis and Management - Google Books. [cited 2020 Feb 11]. Available from: https://books.google.com.ng

7. Sheehan, H. L., \& Summers, V. K. (1949). THE SYNDROME OF HYPOPITUITARISM1. QJM: An International Journal of Medicine, 18(4), 319. 378.

8. Himabindu, P., Sowjanya, R., \& Vasudha, M. (2015). Reproductive Outcome in a Rare Case of Empty Sella Syndrome. IOSR Journal Dent Medical Science, 14(4):18-19.

9. De Marinis, L., Bonadonna, S., Bianchi, A., Maira, G., \& Giustina, A. (2005). Primary empty sella. The Journal of Clinical Endocrinology \& Metabolism, 90(9), 5471-5477.

10. Kumar, K., Khalid, M., Fadhil, A., Lamba, P., Basha, S. A., \& El, S. A. (2014). Empty Sella Syndrome. Proceedings of the 6th Annual Scientific Meeting of Gulf Medical University, 5th \& 6th November, 67-71.

11. Agarwal, J. K., Sahay, R. K., Bhadada, S. K., Reddy, V. S., \& Agarwal, N. K. (2001). Empty sella syndrome. J Indian Acad Clin Med,2(3), 198-202.

12. Bardoloi, P. S., \& Abba-Aji, A. (2017). A case of empty Sella syndrome presenting with neuropsychiatric Symptoms. J Neurol Neurosci, 8(3).

13. Bonneville, J. F. (2016). Empty sella. In: MRI of the Pituitary Gland. Springer International Publishing; 307-313. 